\title{
POST-ANAESTHETIC JAUNDICE DUE TO GLUCOSE-6-PHOSPHATE DEHYDROGENASE DEFICIENCY
}

\author{
J.M. ShaPLEY, M.D., C.R.C.P. (c) AND J.R. Wilson, M.B.B.S., D.T.M. \& H. ${ }^{*}$
}

IN THE LAST FEW YEARS reports have been appearing in the literature of hepatic failure and high output renal failure after the administration of methoxyflurane. The authors are not aware that the type of jaundice described in this case has been reported previously.

Mr. B. a 27-year-old male of Yugoslavian origin, with chronic serous otitis media, was admitted to hospital on November 22, 1971, for a left tympanoplasty. Physical examination was normal except for the ear problem. Family history and past medical history were non-contributory. There was no previous history of jaundice, blood transfusions or injections, or recent colds, sore throats, lymphadenopathy or abdominal pain, and no history of medication or drugs of any kind, other than ear drops of "unknown nature."

Pre-operative urinalysis was normal. Haemoglobin was $14.6 \mathrm{gm}$.

Pre-medication of meperidine $100 \mathrm{mg}$, with atropine $0.6 \mathrm{mg}$, was given one hour before operation on November 23, 1971. Induction of anaesthesia was carried out with thiopentone $300 \mathrm{mg}$, d-tubocurarine $3 \mathrm{mg}$ and succinylcholine $100 \mathrm{mg}$. Following induction the patient received 1.5 per cent methoxyflurane with nitrous oxide and oxygen in a ratio of 4:2 litres per minute. Maintenance for four and one half hours was carried out with 0.75 per cent methoxyflurane. The patient's condition during operation was quite satisfactory, although the surgeon did remark, on making his incision, that there was more than the usual amount of bleeding. He made a normal recovery from the anaesthetic and was returned to the ward in satisfactory condition.

On the second post-operative day it was noticed that the patient was jaundiced and there was a slight left sided facial weakness (presumably due to trauma to left facial nerve at operation). He was afebrile, pulse was 68 per minute and regular, blood pressure was $140 / 70 \mathrm{~mm} \mathrm{Hg}$. There was no hepatomegaly or abdominal tenderness.

Drugs received pre-operatively and in the immediate post-operative period were - meperidine, atropine, secobarbital, dimenhydrinate, propoxyphene and one dose of ampicillin ${ }^{\circledR}$.

The laboratory findings were as follows:

${ }^{\circ}$ From Department of Anaesthesia, University of Toronto and Sunnybrook Hospital.

Canad. Anaesth. Soc. J., vol. 20, no. 3, May 1973 


\begin{tabular}{|c|c|c|c|c|c|c|c|}
\hline Urine & React. & Sp. Gr. & Alb. & Sugar & Acet. & Bile & Urobilin \\
\hline Nov. $\begin{array}{r}22 \\
25 \\
26\end{array}$ & 5.0 & $\frac{1.011}{-}$ & - & - & 二 & $\begin{array}{c}\overline{1+} \\
\text { neg. } \\
\text { for free } \mathrm{Hgb}\end{array}$ & trace \\
\hline 29 & & & & & & $\begin{array}{c}\text { neg. } \\
\text { for free } \mathrm{Hgb}\end{array}$ & trace \\
\hline
\end{tabular}

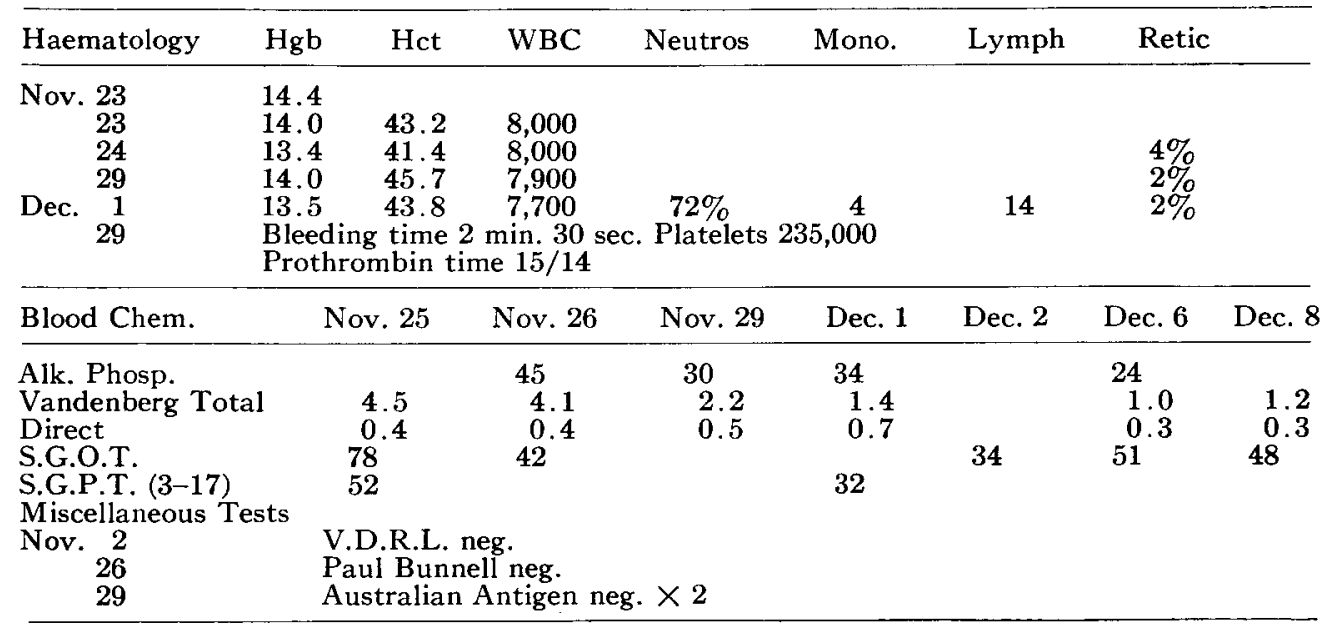

The increase in unconjugated or indirect bilirubin suggested prehepatic jaundice.

Liver biopsy was performed on December 6 , thirteen days post-operatively and the pathologist's report noted that there were histological features suggesting a mild degree of hepatic cellular damage, associated with increased stainable iron, probably secondary to the basic disturbance. The differential diagnosis was mild viral hepatitis or hepato-cellular damage due to a toxic drug, an anaesthetic agent or other medication. The bone marrow biopsy showed slightly increased stainable iron and mild erythroid hyperplasia. The serum iron was 102 , total iron binding capacity 340 , which is normal. Red cell survival measured with ${ }^{51}$ chromium labelled cells was found to be 11 days, the normal being 26 days \pm 3 . This indicated haemolysis. With the laboratory findings indicating a decreased red cell survival and a haemolytic process, glucose-6-phosphate dehydrogenase screening was done. The patient was found to be completely deficient in G-6-P.D. The jaundice would appear to be explainable on the basis of haemolysis. However, the changes noted in the liver biopsy did not exclude the possibility that this patient had a mild hypersensitivity reaction to methoxyflurane. We do not know whether methoxyflurane or one of its derivatives is responsible for inducing haemolysis. Caucasians and other population groups with a G-6-P.D. deficiency comprise a heterogeneous collection compared with the Negro males, with respect to the properties of the enzyme activity in the tissue cells of the body. 
Young ${ }^{11}$ has estimated that glucose-6-phosphate dehydroxgenase (G-6-P.D.) deficiency in red cells may be demonstrable in more than one hundred million persons. The most common form is found in Negroes, with enzyme activity reduced to 10 per cent to 15 per cent of normal. Reduced activity of the enzyme is associated with deficient formation of the reduced form of nicotinamide adenine dinucleotide phosphate (N.A.D.P.H.) and inability to maintain reduced glutathione (G.S.H.) in the face of certain challenges. More than forty drugs which are converted in the body to oxidant compounds have been shown to produce haemolysis in these subjects. These include primaquine, pamaquine, para-amino salicylic acid, phenacetin and sulfonamides. At the time of discharge this patient's prothrombin time and serum bilirubin were normal. However, liver enzymes were still slightly elevated.

This case is presented primarily as an unusual case of jaundice following anaesthesia with a halogenated agent. It illustrates the point that the aetiology of jaundice following anaesthesia, particularly with fluorinated agents, should be explored in detail and attempts to arrive at a conclusive diagnosis must be made. In this case the aetiological factor turned out to be rare indeed.

On discharge the patient was advised against having halogenated agents in any future anaesthetic procedure and, in addition, attention was drawn to the fact that he should not be exposed to any oxidant drugs likely to cause haemolysis.

\section{REFERENCES}

1. Burka, E.R., Weaver, Z., \& Marks, P.A. Clinical spectrum of haemolytic anaemia, associated with glucose-6-phosphate dehydrogenase deficiency. Annals of Internal Medicine, 64: 817 (1966).

2. BECKER, F.P. Fatal massive liver necrosis after repeated methoxyflurane anaesthesia. Lancet C: 719 (1970).

3. Lischiner, M.W., MacNabb, G.M., \& Galambos, J.T. Fatal hepatic necrosis following surgery. Archives of Internal Medicine 725 (1967).

4. Elxington, S.G., Goffinet, J.A., \& Conn, H.O. Renal and hepatic injury associated with methoxyflurane anaesthesia. Annals of Internal Medicine C: 1225, (1968).

5. Bremner, A.I. \& Marshall, M.K. Recurrent hepatitis due to methoxyflurane anaesthesia. New England Medical Journal 17: 284 (1971).

6. KATz, S. Hepatic coma associated with methoxyflurane anaesthesia. American Journal of Digestive Diseases 15: 733 (1970).

7. Stefanini, M., Herland, A., \& Kosyak, E.A. Fatal massive necrosis of the liver after repeated exposure to methoxyflurane. Anesthesiology 32: 374 (1970).

8. Lindenbaum, J., \& Leifer, E. Hepatic necrosis associated with halothane anaesthesia. New England Journal of Medicine 268: 10.523 ( 1963 ).

9. Klein, W. \& JefFries, G. Hepatotoxicity after methoxyflurane administration. Journal of American Medical Association 197: 12.1037 ( 1966 ).

10. Pannier, R. \& Freeman, B. Toxicity following methoxyflurane anaesthesia. Journal of the American Medical Association 214: 1.86. (1970).

11. Young, L.E. Cecil's Textbook of Medicine. Ed. Loeb. Philadelphia and London. W.B. Saunders, Publisher. 12th Edition, 1968, p. 1036. 